\title{
Etnomatematika: Arsitektur Rumah Adat di Sukabumi sebagai Bahan Pembelajaran Matematika di Pendidikan Dasar
}

\author{
Aritsya Imswatama ${ }^{1}$, Indra Zultiar ${ }^{2}$ \\ ${ }^{1,2}$ Universitas Muhammadiyah Sukabumi \\ 1iaritsya@gmail.com, ${ }^{2}$ indrazultiar@gmail.com
}

\begin{tabular}{l}
\hline \hline Article Info \\
\hline Article history: \\
Received Agt $15^{\text {th }}, 2019$ \\
Revised Oct $30^{\text {th }}, 2019$ \\
Accepted Nov $20^{\text {th }}, 2019$
\end{tabular}

Keywords:

Ethnomathematics;

Architecture of

Traditional Houses;

Elementary Education
This study aims to describe matters relating to mathematics in the architecture of traditional houses in Sukabumi. This type of research is a qualitative research with an ethnographic approach. Data collection techniques used in this study were interviews, observation, and documentation. Data analysis techniques used are data reduction, data display, verification and inference. The results of this study indicate that in the architecture there are mathematical elements including geometry consisting of rectangles, squares, and lengths. The results of this study are expected to be used as an innovation in mathematics learning in elementary schools.

\section{Abstrak}

Kata Kunci:

Etnomatematika; Arsitektur Rumah Adat; Pendidikan Dasar
Penelitian ini bertujuan untuk mendeskripsikan hal-hal yang berkaitan dengan matematika dalam arsitektur rumah adat di Kabupaten Sukabumi. Jenis penelitian ini adalah penelitian kualitatif dengan pendekatan etnografi. Teknik pengumpulan data yang digunakan dalam penelitian ini adalah wawancara, observasi dan dokumentasi. Teknik analisis data yang digunakan menggunakan reduksi data, sajian data, verifikasi, dan penyimpulan. Hasil penelitian ini menunjukkan bahwa dalam arsitektur tersebut terdapat unsur matematis diantaranya adalah geometri yang terdiri dari persegi panjang, persegi, dan jajargenjang. Hasil penelitian ini diharapkan dapat digunakan sebagai inovasi pembelajaran matematika di Sekolah Dasar. 
120| Imswatama dan Zultiar: Etnomatematika: Arsitektur Rumah Adat di Sukabumi sebagai...

\section{PENDAHULUAN}

Indonesia merupakan negara yang mempunyai banyak kebudayaan. Salah satu kebudayaan yang ada di Indonesia adalah kebudayaan Sunda. Namun karena pengaruh globalisasi kebudayaan Sunda hampir sudah tidak digunakan lagi. Hal ini terlihat dari banyaknya siswa Sekolah Dasar yang tidak mengetahui nama-nama bangunan khas kebudayaan Sunda. Padahal kebudayaan merupakan jati diri bangsa yang harus selalu dilestarikan. Salah satu cara untuk mengenalkan dan melestarikan kebudayaan adalah dengan mengintegrasikan dengan materi yang diajarkan di sekolah. Etnomatematika merupakan salah satu cara untuk mengaitkan materi matematika dengan kebudayaan.

Menurut Tandiling (2013), etnomatematika adalah matematika yang diterapkan oleh kelompok budaya tertentu, kelompok buruh/petani, anakanak dari masyarakat kelas tertentu, kelas-kelas profesional ,dan sebagainya. Jika dipandang dari sudut pandang riset maka etnomatematika dapat didefinisikan sebagai antropologi budaya (cultural antropology of mathematics) dari matematika dan pendidikan matematika.

Menurut D'Ambrosio (Puspadewi dan Putra, 2014), matematika yang dibelajarkan di sekolah dikenal dengan academic mathematics, sedangkan etnomatematika merupakan matematika yang diterapkan pada kelompok budaya yang teridentifikasi seperti masyarakat, suku, kelompok buruh, anak-anak dari kelompok usia tertentu, kelas profesional, dan lain sebagainya. Sehingga dapat dikatakan bahwa etnomatematika merupakan matematika yang muncul sebagai akibat pengaruh kegiatan yang ada di lingkungan yang dipengaruhi oleh budaya.

Matematika sebagai ilmu dasar perlu mengkaji dan menelaah dasardasar ilmu hitung atau komputasi yang diterapkan dalam masyarakat untuk memperkaya pengembangan matematika. Dengan lahirnya etnomatematika, seseorang dapat melihat keberadaan matematika sebagai suatu ilmu yang tidak hanya berlangsung di kelas. Menurut Rosa dan Orey (2011) etnomatematika menyajikan konsep matematika yang sesuai dengan kurikulum di sekolah dengan mengaitkan budaya dan pengalaman sehari-hari siswa. sedangkan menurut Arisetyawan dkk (2014) alasan 
bahwa ethnomatematika penting untuk pembelajaran matematika di sekolah karena ethnomatematika dapat menjembatani antara latar belakang pengetahuan siswa dengan pelajaran matematika di sekolah. Oleh karena itu diharapkan dengan pembelajaran matematika yang dikaitkan dengan kebudayaan lokal akan menambah motivasi dan pemahaman konsep siswa serta dapat menjadi salah satu inovasi dalam pembelajaran matematika di sekolah.

Etnomatematika dalam penelitian ini merupakan kajian matematis terhadap arsitektur rumah adat Suku Sunda di Sukabumi. Tujuan dari penelitian ini adalah untuk mengetahui unsur matematis yang terdapat pada rumah adat tersebut yang nantinya dapat digunakan sebagai bahan pembelajaran matematika di Sekolah Dasar. Penelitian ini sesuai dengan penelitian yang telah dilakukan oleh Supriyati dkk(2019) tentang arsitektur di Suku Sasak Lombok. Kajian tersebut mengungkap tentang angka yang dipraktikkan oleh nenek moyang masyarakat Suku Sasak sejak dulu. Perbedaan dengan penelitian ini adalah dalam penelitian ini akan diungkapkan tentang jenis-jenis bangun datar yang terdapat dalam arsitektur rumah adat di Kabupaten Sukabumi.

\section{METODE PENELITIAN}

Jenis penelitian ini merupakan penelitian kualitatif dengan pendekatan etnografis. Menurut Sugiyono (2012) metode penelitian kualitatif merupakan metode penelitian yang dilakukan pada kondisi yang alamiah dan lebih banyak digunakan untuk penelitian di bidang antropologi budaya. Teknik pengumpulan data yang digunakan dalam penelitian ini adalah wawancara dan dokumentasi. Informan dalam penelitian ini adalah warga masyarakat Suku Sunda yang mengetahui mengenai kebudayaan di daerah Sunda. Teknik analisis data yang digunakan adalah reduksi data, sajian data, verifikasi, dan penyimpulan. 


\section{HASIL PENELITIAN DAN PEMBAHASAN Arsitektur Rumah Adat Sunda}

Suku Sunda merupakan suku yang mendiami sebagian besar Jawa Barat termasuk kawasan Geopark Ciletuh Sukabumi. Suku ini mempunyai kebudayaan khas seperti suku-suku pada umumnya di Indonesia. Salah satunya adalah dari segi bangunan tradisional. Konsep dasar bangunan khas Suku Sunda adalah bangunan yang berbentuk panggung. Bentuk panggung tersebut bertujuan untuk menghindari masalah dari lingkungan yang bisa mengancam penghuninya.
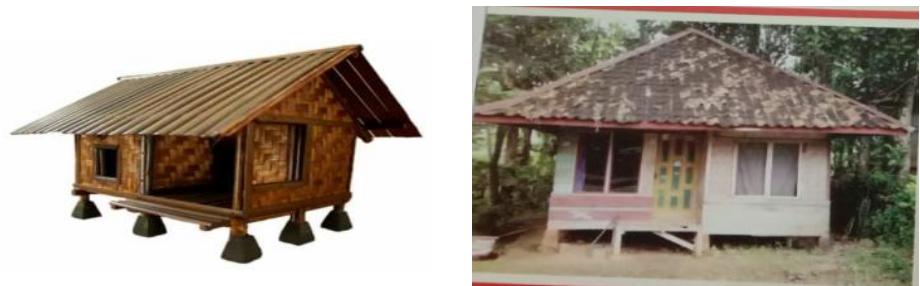

\section{Gambar 1. Contoh Rumah Adat Sunda}

Dilihat berdasarkan bentuk atapnya, rumah adat tradisonal Sunda terbagi atas beberapa ciri, adapun jenis-jenisnya adalah sebagai berikut:

a. Jolopong merupakan rumah dengan atap pelana yang bentuknya memanjang;

b. Perahu Kumurep merupakan rumah dengan bentuk atap perisai disebut perahu kemureb oleh masyarakat Sunda karena bentuk atap seperti perahu terbalik;

c. Julang Ngapak merupakan rumah dengan bentuk atapnya seperti sayap burung yang sedang terbang;

d. Badak Helay merupakan rumah dengan bentuk atap seperti seekor badak yang sedang membuka mulut;

e. Tagog Anjing merupakan rumah dengan bentuk seperti seekor anjing yang sedang duduk;

f. Capit Gunting merupakan rumah dengan bentuk atap yang bagian atasnya saling menyilang berbentuk gunting.

Bentuk pondasi pada rumah adat Suku Sunda cukup unik, yaitu kolom bangunan hanya diletakkan di atas sebuah batu datar yang sudah 
terbentuk di alam, tujuannya adalah untuk menghindari keretakan pada saat terjadi gempa. Sedangkan bentuk lantai panggung bertujuan agar sirkulasi udara dari bawah lantai berjalan dengan baik hal ini bertujuan untuk mengurangi kelembaban pada lantai bangunan. Lantai rumah adat Sunda terbuat dari "pelupuh" (bambu yang sudah dibelah). Tujuan pembuatan lantai dari pelupuh ini adalah agar udara yang masuk melalui kolong rumah dapat masuk ke ruangan.

Dinding, pintu, dan jendela terbuat dari anyaman bambu yang bertujuan agar udara dapat masuk celah-celah anyaman bambu tersebut. Hal ini mengakibatkan suhu di dalam ruangan tidak panas. Bagian atap pada rumah adat Sunda terbuat dari ijuk berfungsi untuk melindungi penghuni yang berada di dalamnya. Alasan pemilihan ijuk sebagai material atap adalah karena ijuk merupakan material yang dapat menyerap panas dengan baik sehingga tidak menimbulkan suasana gerah di dalam rumah. "Tritisan" pada bagian depan rumah mempunyai panjang kira-kira 2 meter hal ini bertujuan agar dinding bangunan tidak terkena langsung cahaya matahari sehingga dinding yang fungsinya sebagai penyekat tidak panas dan ruangan di dalamnya tetap dingin.

\section{Unsur Matematis pada Rumah Adat Sunda}

Pada rumah adat Sunda tanpa disadari terdapat unsur matematika yang dapat diterapkan sebagai bahan pembelajaran di kelas diantaranya adalah bangun datar. Menurut Hardi (2009) bangun datar adalah bangun dua dimensi yang hanya memiliki panjang dan lebar, yang dibatasi oleh garis lurus atau lengkung. Bentuk bangunan rumah adat Sunda dapat dijadikan sebagai media pembelajaran matematika di sekolah yaitu pada materi tentang pengenalan bangun datar, sifat bangun datar maupun aplikasi konsep bangun datar untuk menyelesaikan masalah dalam kehidupan sehari-hari. Dengan menggunakan media ini diharapkan siswa mempunyai pengetahuan lebih tentang bangun datar yang ada di lingkungan tempat tinggalnya. 
a. Bentuk Bangun Persegi Panjang

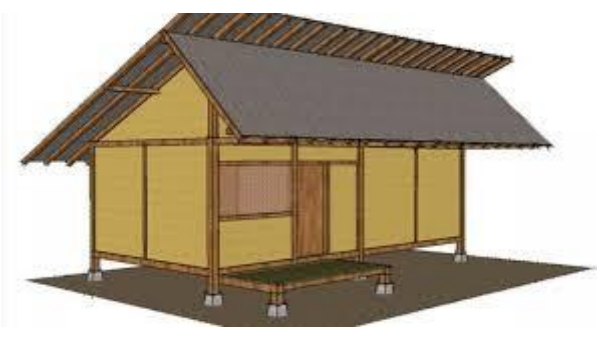

\section{Gambar 2. Dinding Samping Rumah}

Pada Gambar 2 di atas, dinding samping rumah dapat dimodelkan secara geometri seperti pada Gambar 3 di bawah ini.
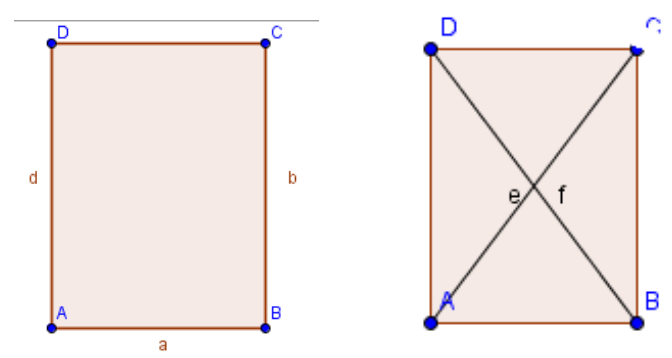

\section{Gambar 3. Analisis Pemodelan Bangun Datar}

Pada gambar tersebut diketahui bahwa pemodelan tersebut berbentuk bangun datar yang memiliki empat sisi. Selanjutnya jika dianalisis lebih lanjut terdapat beberapa sifat yang ditemukan diantaramya adalah

1) $A B \neq C B$, dan $A D \neq C D$

2) $m \angle A=m \angle B=m \angle C=m \angle D=90^{\circ}$

3) $A C=B D$

4) Mempunyai 2 simetri putar dan 2 simetri lipat.

Berdasarkan analisis sifat-sifat bangun datar tersebut dapat disimpulkan bahwa terdapat unsur persegi panjang pada rumah adat Sunda. 
b. Bentuk Bangun Jajar Genjang
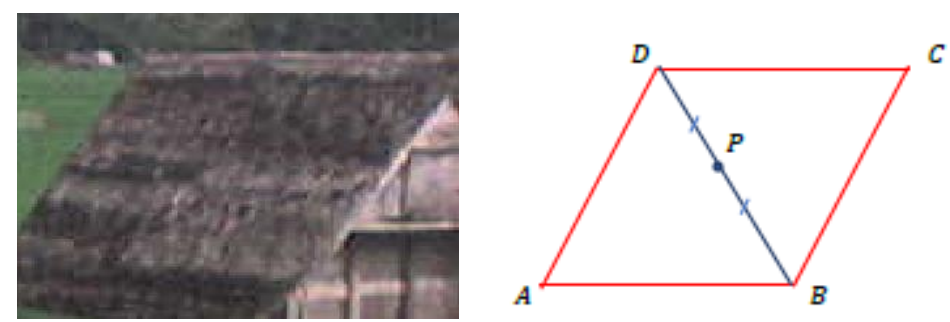

Gambar 4. Bentuk Atap Rumah Adat Sunda

Pada Gambar 4 di atas diketahui bahwa pemodelan atap rumah tradisonal Suku Sunda tersebut berbentuk bangun datar yang memiliki empat sisi. Selanjutnya jika dianalisis lebih lanjut terdapat sifat-sifat yang menunjukkan bahwa bangun tersebut merupakan bangun datar jajargenjang. Adapun analisis sifat-sifatnya adalah sebagai berikut:

1) $A B \neq C D ; B C \neq A D$

2) $\angle A=\angle D ; \angle B=\angle C$

3) Jumlah sudut yang berhadapan besarnya $180^{\circ}$

Berdasarkan analisis sifat-sifat bangun datar tersebut dapat disimpulkan bahwa terdapat unsur jajargenjang pada rumah adat Sunda. Hal ini sesuai dengan pendapat Siswoyo (2011) bahwa sifat-sifat jajargenjang adalah sisi-sisi yang berhadapan sejajar dan sama panjang, sudut-sudut yang berhadapan sama ukurannya, diagonal jajargenjang membagi daerah menjadi sama besar, diagonal-diagonalnya saling membagi dua sama panjang.

c. Bentuk Bangun Segitiga
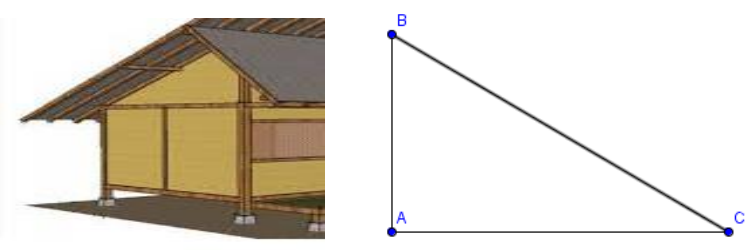

Gambar. 5. Dinding Bagian Atas Rumah Adat Sunda 
126| Imswatama dan Zultiar: Etnomatematika: Arsitektur Rumah Adat di Sukabumi sebagai...

Diketahui bahwa pemodelan dinding bagian atas dari rumah adat Sunda di atas berbentuk bangun yang memiliki tiga sisi. Jika dianalisis lebih lanjut terdapat sifat-sifat yang menunjukkan bahwa bangun tersebut merupakan segitiga.

\section{Potensi Etnomatematika yang dapat Dikembangkan dalam} Pembelajaran Matematika di Sekolah Dasar.

Unsur matematika yang terdapat dalam arsitektur rumah adat Sunda dapat dijadikan guru sebagai media pembelajaran matematika, misalnya dalam materi pengenalan jenis bangun datar, sehingga akan memudahkan siswa dalam melakukan abstraksi tentang bangun geometri. Hal ini sesuai dengan manfaat media pembelajaran bahwa menurut Widyantini dan Sigit (2009), dengan media pembelajaran siswa dapat memperoleh berbagai pengalaman nyata sehingga materi pembelajaran mudah dipahami serta dapat mendorong siswa mengingat apa yang sudah dipelajari. Selain itu menurut Fajriyah (2018) etnomatematika merupakan salah satu inovasi dalam mendukung literasi matematika. Dengan penerapan pembelajaran matematika berbasis budaya dapat menjadikan pembelajaran matematika lebih bermakna dan kontekstual yang berkaitan erat dengan konteks kebudayaan lokal. Selain itu pembelajaran matematika berbasis budaya akan menjadi alternatif pembelajaran yang menarik, menyenangkan, dan inovatif karena memungkinkan terjadinya pemaknaan secara kontekstual berdasarkan pada pengalaman siswa sebagai anggota suatu masyarakat budaya sehingga diharapkan dapat ikut mendukung gerakan literasi. Adapun contoh penerapan adalah sebagai berikut:

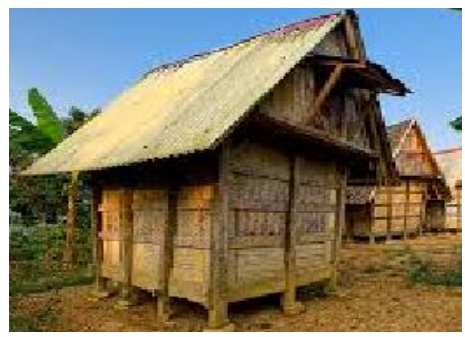

Gambar 6. Contoh Penerapan 
Perhatikan gambar di atas!

1. Apa nama bangunan di atas?

2. Apa fungsi bangunan tersebut?

3. Dari gambar tersebut, sebutkan jenis bangun datar yang kalian ketahui!

Gambar di atas merupakan contoh pengembangan etnomatematika dalam pembelajaran matematika di kelas. Dari gambar di atas siswa dilatih untuk mengamati secara langsung fenomena budaya yang ada disekitarnya, dalam hal ini adalah mengamati beberapa bangunan adat di daerahnya. Kemudian siswa dituntut untuk membuat sketsa bangun tersebut secara geometri. Setelah siswa menyusun sketsa maka siswa dituntut untuk memcahkan permasalahan tersebut dengan menggunakan konsep matematika. Hal ini dapat digambarkan dengan sketsa berikut.

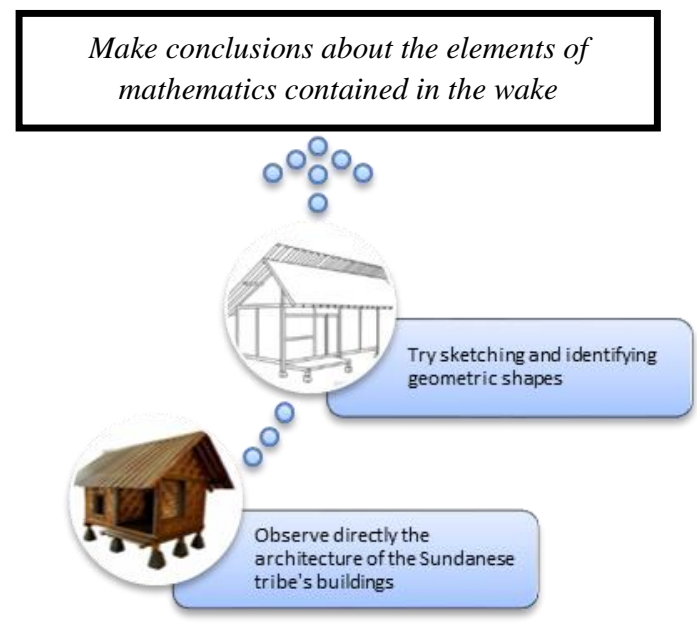

\section{Gambar 7. Alur Metode Saintifik}

Dengan menerapkan pembelajaran ini, siswa akan dilatih untuk berpikir secara ilmiah. Sehingga melalui metode ilmiah, konsep pengetahuan siswa dibentuk berdasarkan fakta-fakta ilmiah yang dimulai dengan melakukan pengamatan. Ini sesuai dengan pendapat Richardo (2016) yang mengatakan bahwa fakta atau fenomena adalah objek ilmiah yang digunakan untuk membangun pengetahuan yang melibatkan unsur- 
128| Imswatama dan Zultiar: Etnomatematika: Arsitektur Rumah Adat di Sukabumi sebagai...

unsur logika dan pengalaman. Guru dapat mengembangkan lebih banyak dan mengadaptasinya ke bahan pembelajaran dan keadaan di lingkungan. Sehingga para guru tidak hanya menyampaikan informasi tentang materi pelajaran tetapi juga tentang budaya.

\section{SIMPULAN}

Dari hasil penelitian ini dapat disimpulkan bahwa terdapat unsur matematis dari arsitektur bangunan rumah adat Sunda yang dapat diterapkan dalam pembelajaran matematika diantaranya adalah segitiga dan segiempat. Penerapan etnomatematika dalam pembelajaran matematika di kelas diharapkan dapat meningkatkan motivasi, kemampuan berfikir ilmiah dan menambah wawasan peserta didik terkait dengan kebudayan dan kearifan lokal yang ada di lingkungannya.

\section{DAFTAR PUSTAKA}

Arisetyawan, Andika, dkk. (2014). Study of Ethnomathematics: A lesson from the Baduy Culture. International Journal of Education and Research, 2(10), ISSN. 2201-6333.

Fajriyah, E. (2018). Peran Etnomatematika Terkait Konsep Matematika dalam Mendukung Literasi. Prosiding Seminar Nasional Matematika, 114-119.

Hardi. (2009). Pandai Berhitung Matematika. Jakarta: Pusat Perbukuan, Departemen Pendidikan Nasional.

Puspadewi, K. R., Putra, I G.N.N. (2014). Etnomatematika di Balik Kerajinan Anyaman Bali. Jurnal Matematika. 4(2). Retrieved from https://ojs.unud.ac.id/index.php/jmat/article/view/12552.

Richardo. (2016). Peran Etnomatematika dalam Penerapan Pembelajaran Matematika pada Kurikulum 2013. Jurnal Literasi, 7(2), 118-125. Retrieved from http://almaata.ac.id/ejournal1532/index.php/LITERASI/article/dow nload/383/351.

Rosa, M. \& Orey, D.C. (2011). Ethnomathematics: The Cultural Aspects of Mathematics. Revista Latinoamericana de Etnomatematica, 4(2), 
32-54. Retrieved from https://documat.unirioja.es/descarga/articulo/ 3738356.pdf.

Siswoyo, B. (2011). Peningkatan Hasil Belajar Sifat-sifat Segiempat dengan Pendekatan STAD di Kelas VII SMP Negeri Kutalimbaru. Jurnal Kreano, 2(2), Retrieved from https://journal.unnes.ac.id/nju/index.php/kreano/article/view/2619.

Sugiyono. (2013). Metode Penelitian Pendidikan Pendekatan Kuantitatif, Kualitatif, dan $R \& Y$. Bandung: Alfabeta.

Supriyati dkk, (2019). Ethnomathematics In Sasaknese Architecture. Journal on Mathematics Education, 10(1), 47-58. Retrieved from https://ejournal.unsri.ac.id/index.php/jme/article/view/5383.

Tandiling, Edi. (2013). Pengembangan Pembelajaran Matematika Sekolah dengan Pendekatan Etnomatematika Berbasis Budaya Lokal Sebagai Upaya Untuk Meningkatkan Kualitas Pembelajaran Matematika di Sekolah. Prosiding Seminar Nasional Matematika dan Pendidikan Matematika. ISBN: 978_979-16353-9-4.

Widyantini dan Sigit. (2009). Pemanfaatan Alat Peraga dalam Pembelajaran Matematika SMP. Yogyakarta: Departemen Pendidikan Nasioal Direktorat Jenderal Pendidikan Dasar dan Menengah PPPPTK. 
130| Imswatama dan Zultiar: Etnomatematika: Arsitektur Rumah Adat di Sukabumi sebagai... 